\title{
O efeito cicatrizante do extrato etanólico das folhas de Himatanthus obovatus (Müll
}

\section{Arg.) Woodson}

The healing effect of the ethanol extract of the leaves of Himatanthus obovatus (Müll Arg.)

Woodson

El efecto curativo del extracto de etanol de las hojas de Himatanthus obovatus (Müll Arg.)

Woodson

\section{Resumo}

Himatanthus obovatus, conhecida como janaguba, é encontrada no Nordeste brasileiro. As suas folhas são usadas para hipertensão, manchas na pele e como antitumoral, no entanto ainda são incipientes os estudos quanto à ação cicatrizante. O estudo teve como objetivo analisar o perfil fitoquímico e o efeito cicatrizante do extrato etanólico das folhas de $H$. obovatus em camundongos. A prospecção fitoquímica do extrato foi realizada pelo teste colorimétrico. Os geis (carbopol mais o extrato) foram confeccionados obtendo as doses de 50, 75 e $100 \mathrm{mg} / \mathrm{Kg}$. O carbopol, água destilada, pomada Nebacetin ${ }^{\circledR}$ e o extrato (gel) foram aplicados de forma tópica na área da lesão dos camundongos como controle negativo (CN), solvente (CS), positivo (CP) e grupo tratamento, respectivamente, durante 21 dias. As feridas foram registradas nos dias 0, 7, 14 e 21 dias para análise macroscópica e histológica após 21 dias. Os dados foram analisados pelo teste de Kruskal-Wallis ou Tukey $(\mathrm{p}<0,05)$. Os resultados mostraram a presença de taninos, açúcares redutores, fenóis, flavonoides e alcaloides. No intergrupo, o extrato não apresentou diferença significativa da área da lesão quando comparado com o CP após o $14^{\circ}(50$ e $75 \mathrm{mg} / \mathrm{kg})$ e $21^{\circ}$ dias para todas as doses. No intragrupo, todas as doses do extrato apresentaram redução após o $14^{\circ}$ e no $21^{\circ}$ para $100 \mathrm{mg} / \mathrm{Kg}$. O extrato mostrou aumento 
significativo de fibroblastos e área de colágeno em 50 e $100 \mathrm{mg} / \mathrm{Kg}$. Sendo assim, o extrato apresenta potencial para ser explorado como um fitoterápico que possa ser utilizado como gel cicatrizante.

Palavras-chave: Feridas; Janaguba; Planta medicinal.

\begin{abstract}
Himatanthus obovatus, known as janaguba, is found in Northeastern Brazil. Its leaves are used for hypertension, skin blemishes and as an anti-tumor, however studies regarding its healing action are still incipient. The study aimed to analyze the phytochemical profile and the healing effect of the ethanol extract of $H$. obovatus leaves in mice. The phytochemical prospection of the extract was carried out by the colorimetric test. The gels (carbopol plus the extract) were made with doses of 50,75 and $100 \mathrm{mg} / \mathrm{kg}$. Carbopol, distilled water, Nebacetin ${ }^{\circledR}$ ointment and extract (gel) were applied topically to the area of the mice lesion as negative control (NC), solvent (SC), positive (PC) and treatment group, respectively, for 21 days. Wounds were recorded on days 0, 7, 14 and 21 days for macroscopic and histological analysis after 21 days. Data were analyzed using the Kruskal-Wallis or Tukey test $(\mathrm{p}<0.05)$. The results showed the presence of tannins, reducing sugars, phenols, flavonoids and alkaloids. In the intergroup, the extract did not show significant difference in the area of the lesion when compared to the PC after the 14th $(50$ and $75 \mathrm{mg} / \mathrm{kg}$ ) and $21 \mathrm{st}$ days for all doses. In the intragroup, all doses of extract showed a reduction after the 14th and $21 \mathrm{st}$ to $100 \mathrm{mg} / \mathrm{kg}$. The extract showed a significant increase in fibroblasts and collagen area at 50 and $100 \mathrm{mg} / \mathrm{kg}$. Thus, the extract has the potential to be explored as an herbal medicine that can be used as a healing gel.
\end{abstract}

Keywords: Medicinal plant; Janaguba; Wound.

\begin{abstract}
Resumen
Himatanthus obovatus, conocido como janaguba, se encuentra en el noreste de Brasil. Sus hojas se utilizan para la hipertensión, imperfecciones cutáneas y como antitumoral, sin embargo los estudios sobre su acción cicatrizante aún son incipientes. El estudio tuvo como objetivo analizar el perfil fitoquímico y el efecto curativo del extracto etanólico de hojas de $H$. obovatus en ratones. La prospección fitoquímica del extracto se realizó mediante la prueba colorimétrica. Los geles (carbopol más el extracto) se elaboraron con dosis de 50,75 y $100 \mathrm{mg} / \mathrm{kg}$. Se aplicaron tópicamente Carbopol, agua destilada, pomada de Nebacetinß y el extracto (gel) al área de la lesión del ratón como control negativo $(\mathrm{CN})$, solvente $(\mathrm{CS})$, positivo $(\mathrm{CP})$ y grupo de tratamiento, respectivamente, durante 21 días. Las heridas se registraron los días $0,7,14$ y 21 días para análisis macroscópico e histológico después de 21 días. Los datos se analizaron mediante la prueba de Kruskal-Wallis o Tukey ( $\mathrm{p}<0,05)$. Los resultados mostraron la presencia de taninos, azúcares reductores, fenoles, flavonoides y alcaloides. En el intergrupo, el extracto no mostró diferencia significativa en el área de la lesión en comparación con el CP después de los días 14 (50y $75 \mathrm{mg} / \mathrm{kg}$ ) y 21 para todas las dosis. En el intragrupo, todas las dosis del extracto mostraron una reducción después del 14 y 21 a $100 \mathrm{mg} / \mathrm{kg}$. El extracto mostró un aumento significativo de fibroblastos y área de colágeno a 50 y $100 \mathrm{mg} / \mathrm{kg}$. Por lo tanto, el extracto tiene el potencial de ser explorado como una medicina herbal que puede usarse como gel curativo.
\end{abstract}

Palabras clave: Heridas; Janaguba; Planta medicinal.

\title{
1. Introdução
}

A pele é o maior órgão do corpo humano, sendo constituída por camadas que atuam na termorregulação, proteção, excreção de água e eletrólitos, regeneração e cicatrização do tecido lesionado (Griffiths et al., 2016). A regeneração ocorre por reposição de células parenquimatosas, em que não há dano na lâmina basal, enquanto a cicatrização, por sua vez, é um processo complexo, que ocorre em lesões na lâmina basal e consiste de uma cascata de eventos celulares e moleculares que interagem para a reconstituição do tecido (Darby et al., 2017). Pode-se dividir esse processo em três fases principais: inflamação, proliferação (reepitelização, fibroplasia e angiogênese) e remodelamento, porém muitas vezes, essas fases se sobrepõem e ocorrem simultaneamente (Passaretti et al., 2016).

A fase inflamatória tem duração de um a quatro dias, dependendo da lesão, e é caracterizada por limitar a lesão tecidual e a resposta inflamatória aguda. Nesse período, ocorrem à ativação do sistema de coagulação sanguínea e à liberação de mediadores químicos, como fatores de ativação de plaquetas, fatores de crescimento, serotonina, adrenalina e fatores de complemento (Cooper et al., 2015). A segunda fase (proliferativa) pode durar de cinco a vinte dias, sendo caracterizada pela reepitelização que ocorre precocemente, onde as células epiteliais da borda da ferida começam a proliferar na tentativa de restabelecer a barreira protetora. Ao mesmo tempo, ocorre a proliferação de fibroblastos, sob a ação de citocinas que dão origem a um processo denominado fibroplasia e a proliferação de células endoteliais (angiogênese) e infiltração densa de macrófagos, formando o tecido de granulação (Gensel et al., 2015). A última fase 
(remodelamento) inicia-se no $21^{\circ}$ dia e pode durar meses. Nesta fase, a densidade celular e a vascularização da ferida diminuem, enquanto à maturação e o alinhamento das fibras colágenas aumentam a resistência do tecido e diminuem a espessura da cicatriz, reduzindo a deformidade da mesma (Oh et al., 2014).

As terapias à base de plantas medicinais têm sido amplamente utilizadas para reduzir o tempo de regeneração e cicatrização (Buzzi et al., 2016) e o risco de complicações infecciosas são menores do que os métodos convencionais (Lima et al., 2019). Além disso, estudos de fitocompostos com atividade cicatrizante são estimulados devido ao alto custo no tratamento de feridas (Ribeiro et al., 2019). Os diferentes fitoquímicos, principalmente os flavonoides, apresentam propriedades antioxidantes, anti-inflamatórias e antimicrobianas e têm demonstrado considerável importância no manejo de feridas (Yariswamy et al., 2013).

Mundialmente, o uso de plantas com efeito cicatrizante é bastante utilizado, como as folhas de Plantago major na Europa e das sementes de Syzygium cumini na Ásia (Brasil, 2016). Além dessas plantas serem utilizadas no Brasil, outras espécies também apresentam potencial cicatrizante como as cascas de Schinus terebinthifolius Raddi, as raízes de Solanum nigrum e as folhas de Bryophyllum calycinum e Momordica charantia (Brasil, 2016). A utilização dessas plantas pela população brasileira incentivou o Ministério da Saúde a fortalecer o uso da fitoterapia no Sistema Único de Saúde (SUS) criando, assim, a Política Nacional de Plantas Medicinais e Fitoterápicos (PNPMF). Dentre as plantas preconizadas pela PNPMF, o gênero Himatanthus é proposto como um potencial fitoterápico de uso popular que é usado pela população, contudo necessita de mais estudos (Brasil, 2016; Vieira, 2012).

Himatanthus pertence à família Apocynaceae e possui espécies laticíferas, sendo a maioria de uso popular com atividade antineoplásica, anti-inflamatória, antimicrobiana e analgésica (Almeida et al., 2017). As folhas de H. drasticus e H. bracteatus (Franca et al., 2011), as cascas de H. sucuuba (Calero-Armijos et al., 2020) e o látex da H. articulatus (Silva et al., 2019) apresentam efeito cicatrizante. Contudo, não constam na literatura, trabalhos científicos sobre a atividade cicatrizante do extrato das folhas de H. obovatus (Müll Arg.) Woodson.

Himatanthus obovatus é conhecida popularmente como janaguba, tiborna ou pau-de-leite (Linhares et al, 2013). H. obovatus é uma árvore que pode alcançar de 4 a $5 \mathrm{~m}$ de altura e encontra-se nos estados de Minas Gerais, Bahia, Sergipe, Alagoas, Pernambuco, Rio Grande do Norte, Ceará, Paraíba, Roraima, Maranhão, Pará e Piauí, sendo aplicadas para diferentes fins terapêuticos (Carmo 2015; Spina 2015).

As folhas de $H$. obovatus são utilizadas no tratamento de pressão alta, manchas na pele, espinhas, coceiras e agente antitumoral. As raízes são utilizadas contra a forma amastigota do Tripanosoma cruzi, como antifúngica e leishmanicida (Leishmania donovani). O látex ou leite de H. obovatus tem seu uso contra o câncer (Lucetti et al., 2010; Vale, 2014). A raiz, o caule, o látex do caule e das folhas também são utilizados pela população na cicatrização de feridas (Soares et al., 2015).

As diferentes partes da $H$. drasticus como as folhas, as raizes e o caule são responsáveis pela produção de metabólitos como lupeol e triterpenos que exercem efeito cicatrizante e anti-inflamatório em feridas tegumentar, sendo regulada pelo Fator de Necrose Tumoral (TNF-alfa) e pela Interleucina 2 (IL2) (Vieira, 2018). Além desses metabólitos, os iridoides que também estão presentes em $H$. drascticus e $H$. obovatus, inclusive nas folhas, apresentam diversas atividades farmacológicas, como angiogênicas, anti-inflamatórias e antioxidantes, aumentando a diferenciação celular promovendo a cicatrização (Soares et al., 2016). Os iridoides tendem a aumentar a migração e a proliferação de células inflamatórias, regulada por citocinas e fatores de crescimento estando presentes em diversos medicamentos de uso popular com ação sedativa, antitérmica, hipertensiva e cicatrizante (Moragas, 2006). 
Sendo assim, considerando a importância medicinal de H. obovatus, o presente estudo teve como objetivo detectar os metabólitos primários e/ou secundários, bem como avaliar o potencial de cicatrização do extrato etanólico das folhas de H. obovatus em camundongos (Mus musculus).

\section{Metodologia}

A pesquisa realizada é do tipo experimental e quantitativa conforme descrito por Estrela (2018).

\subsection{Material biológico}

Folhas de H. obovatus foram coletadas na EMBRAPA (5 $5^{\circ} 02^{\prime} 21.36^{\prime \prime} \mathrm{S}$ e $\left.42^{\circ} 47^{\prime} 22,44^{\prime \prime} \mathrm{W}\right)$, Teresina (PI). Exemplares foram identificados e depositados no Herbário Afrânio Fernandes da Universidade Estadual do Piaú (UESPI, Teresina), sob o número de voucher HAF 04655.

\subsection{Preparo do extrato etanólico das folhas de $\boldsymbol{H}$. obovatus}

Folhas de H. obovatus foram secas em estufa à $45^{\circ} \mathrm{C}$ no Laboratório de Genética do Núcleo de Pesquisas em Biotecnologia (NPBio) da UESPI por cinco dias e trituradas em liquidificador até a obtenção de um pó fino. Em seguida, o pó $(190 \mathrm{~g})$ foi submetido a extração exaustiva em etanol absoluto por $72 \mathrm{~h}$. O extrato obtido foi filtrado (Whatman $\left.{ }^{\circledR} \mathrm{n}^{\circ} 2\right)$ e concentrado em evaporador rotativo a baixa pressão $\left(45^{\circ} \mathrm{C}\right)$ e seco com o auxílio de Speed Vacuum a $45^{\circ} \mathrm{C}$ para obter extrato etanólico bruto $(13 \mathrm{~g})$. $\mathrm{O}$ extrato foi concentrado e armazenado a $4^{\circ} \mathrm{C}$ para uso em análises subsequentes.

O extrato etanólico das folhas de H. obovatus (EEFHo) foi diluído em solução salina ( $\mathrm{NaCl}$ 0,9\%) de modo a obter três doses $(500,750$ e $1000 \mathrm{mg} / \mathrm{kg}$ ) que foram pré-selecionadas a partir dos estudos de Sousa et al. (2010), que demonstraram ausência de toxidade e atividade antitumoral em $H$. drasticus. Em seguida, foram confeccionados géis a $10 \%$ de cada dose citada, misturando $60 \mathrm{~g}$ de carbopol (carbomero) e $6 \mathrm{~mL}$ do EEFHo para cada dose e depois foram conservadas em geladeira (COELHO et al., 2010). Sendo assim, as doses utilizadas para avaliar o efeito cicatrizante foram de 50,75 e $100 \mathrm{mg} / \mathrm{kg}$. O carbopol é utilizado como matéria-prima na indústria de cosméticos para fabricação de produtos em gel (Alves, 2020).

\subsection{Prospecção fitoquímica}

Testes de prospecção fitoquímica foram realizados no Laboratório de Química do Instituto Federal do Piauí (IFPI) para a identificação dos principais metabólitos primários e secundários presentes no EEFHo, a fim de detectarem-se os seguintes compostos: açúcares redutores, proteínas e aminoácidos, polissacarídeos, catequinas, alcaloides, flavonoides, taninos e fenóis e saponinas, segundo protocolo proposto por Barbosa et al. (2001). Os testes foram realizados em triplicata e os metabólitos foram considerados como parte da composição do EEFHo quando tiverem resultados positivos na triplicata.

\subsection{Animais e tratamento}

\subsubsection{Animais}

Os animais utilizados foram 30 camundongos machos Swiss (Mus musculus) com 12 semanas de vida, pesando em média $30 \mathrm{~g}$ de peso corpóreo (pc), provenientes do biotério do NPBio da UESPI, Teresina. Os animais foram mantidos em temperatura ambiente controlada $\left(23 \pm 2^{\circ} \mathrm{C}\right)$ com ciclo claro-escuro de $12 \mathrm{~h}$, e em caixas de polipropileno 
adequadas à sua manutenção, água e comida serão oferecidas ad libitum. O projeto foi aprovado pela Comissão de Ética no Uso de Animais (CEUA/UESPI) sob o protocolo No 00049/2017.

Os animais foram divididos em seis grupos experimentais (cinco animais/grupo), sendo acondicionados aleatoriamente em caixas específicas para camundongos. Todos os animais receberam, por via subcutânea, um prétratamento com atropina (relaxante muscular), na dose de $0,04 \mathrm{~mL}$ para cada $30 \mathrm{~g}$ de peso corpóreo, aguardando-se 15 min. para o procedimento anestésico (SOUSA et al., 2015). Subsequentemente, foram anestesiados com cloridrato de xilazina $2 \%(10 \mathrm{mg} / \mathrm{Kg})$ associado ao cloridrato de cetamina $10 \%(100 \mathrm{mg} / \mathrm{Kg})$, por via intramuscular (i.m.). Após a anestesia, foi realizada a tricotomia da região dorsal e assepsia com álcool etílico a 70\%. Foi demarcada uma ferida excisional circular (área de 1,0 $\mathrm{cm}^{2}$ ) na superfície dorsal dos animais com auxílio de um punch cirúrgico para biópsia de pele, atingindo a região dermo-epidérmica.

\subsubsection{Grupos experimentais}

Todos os animais foram distribuídos aleatoriamente nos grupos a seguir: G1 (controle negativo): gel de carbopol; G2 (controle do solvente): água destilada; G3 (controle positivo): pomada Nebacetin ${ }^{\circledR}$ (sulfato de neomicina $5 \mathrm{mg} / \mathrm{g}$ e bacitracina zíncica $250 \mathrm{UI} / \mathrm{g}$ ) para reparação cutânea; G4, 5 e 6 (tratamentos): doses de 50, 75 ou $100 \mathrm{mg} / \mathrm{Kg}$ do EEFHo, respectivamente.

A aplicação tópica de todos os produtos descritos foi realizada após $24 \mathrm{~h}$ do ato cirúrgico uma única vez por dia, durante 21 dias com auxílio de cotonetes descartáveis em quantidade suficiente para cobrir a lesão $\left(1 \mathrm{~cm}^{2}\right)$.

\subsubsection{Avaliação de parâmetros macroscópicos}

Para o registro das feridas, os camundongos foram contidos manualmente, uma vez que se encontravam em estado de alerta, exceto no dia 0 (ato cirúrgico), no qual os animais foram fotografados ainda sob o efeito do anestésico. As imagens foram registradas por meio de uma câmera com captura de imagens, Fujifilm (Finepix L50), com resolução de 12 megapixels. Todas as fotos foram padronizadas com a mesma luminosidade e altura, a câmera foi fixada a $30 \mathrm{~cm}$ em relação à ferida no dorso do animal, utilizando um suporte metálico para apoio da câmera (Souza et al., 2015).

As feridas foram registradas no dia 0 (imediatamente após o ato cirúrgico); $7^{\circ} ; 14^{\circ}$ e $21^{\circ}$ dias pós-cirúrgico. Todas as fotos foram registradas com um paquímetro universal posicionado ao lado dos animais. Para análise da área de lesão e verificação do tecido cicatricial, foi utilizado o programa Image-J, versão 4.5.0.29 for Windows 10 de domínio público, conforme demonstrado pela Barboza (2017).

\subsubsection{Análise histológica}

Após a última aplicação do gel, todos os animais foram sacrificados com o dobro da dose de cetamina (100 $\mathrm{mg} / \mathrm{Kg}$ ) e xilazina $(16 \mathrm{mg} / \mathrm{Kg}$ ). Em seguida, o tecido foi coletado com um bisturi e uma tesoura Íris com cerca de um centímetro além da borda da ferida. O material coletado foi estocado em frascos com formol a $10 \%$ e encaminhado para o laboratório de Histologia da UESPI.

As peças foram incluídas em parafina e submetidas ao processamento histológico. De cada amostra, foram obtidos oito cortes semisseriados $(5 \mu \mathrm{m})$, sendo quatro corados por Hematoxilina-Eosina e quatro com Tricrômico de Masson. A análise do número de fibroblastos, vasos sanguíneos e células inflamatórias foi realizada nos cortes corados com Hematoxilina-Eosina, e a análise da área do colágeno, nos cortes corados com Tricrômico de Masson.

As lâminas histológicas foram submetidas à análise por microscopia óptica e captura de imagem digital. A captura das imagens foi efetuada por meio de uma câmera digital da marca câmera Fujifilm (Finepix L50), com 
resolução de 12 megapixels e acoplada a um microscópio binocular, modelo Coleman com objetivas planacromáticas. As fotomicrografias foram obtidas em aumentos de 40 e 100 vezes e armazenadas no formato JPEG (Joint Photographic Experts Group).

Para a análise quantitativa das células, foi utilizado o programa Image $J$ versão 1.43s. Através do plugin Cell Counter foi realizado a contagem manual das células inflamatórias, fibroblastos e vasos sanguíneos. Com o plugin Threshold Colour foi analisado a quantidade por área de colágeno.

\subsection{Análise estatística}

Os dados obtidos foram analisados pelo teste não paramétrico de Kruskal-Wallis com o teste "a posteriori” de Student-Newman-Keuls $(\mathrm{p}<0,05)$ e os dados paramétricos foram avaliados pelo teste Tukey $(\mathrm{p}<0,05)$ no programa BioEstat 5.3 (AYRES et al., 2007) para realizar a comparação entre as médias dos controles e grupos tratados.

\section{Resultados}

A prospecção fitoquímica do EEFHob detectou a presença de açúcares redutores, taninos, fenóis, flavonoides e alcaloides (Tabela 1).

Tabela 1 - Prospecção fitoquímica do extrato etanólico das folhas de H. obovathus.

\begin{tabular}{lc}
\hline \multicolumn{1}{c}{ Classe de Metabólito } & Resultado \\
\hline Saponinas & - \\
\hline Açúcares redutores & + \\
\hline Taninos & - \\
\hline Proteínas e aminoácidos & - \\
\hline Polissacarídeos & + \\
\hline Fenóis & + \\
\hline Flavonoides & + \\
\hline Alcaloides & - \\
\hline Catequinas & + \\
\hline
\end{tabular}

+ , presente; -, ausente.

Fonte: Autores.

$\mathrm{Na}$ análise macroscópica intergrupo (Figura 1), em todos os dias avaliados $(0,7,14$ e 21$)$ a redução da área da lesão da ferida não foi significativa entre o controle negativo (CN, gel de carbopol) e o solvente (CS, água destilada), evidenciando que o gel de carbapol não interferiu no processo de cicatrização. Nos dias 7, 14 e 21, a redução da área do controle positivo (CP, Nebacetin®) foi significativa em relação ao $\mathrm{CN}$, uma vez que no $\mathrm{CP}$ foi utilizada uma pomada comercializada para fins de cicatrização. O EEFHo mostrou redução significativa da ferida no $14^{\circ}$ e $21^{\circ}$ dias na dose de $50 \mathrm{mg} / \mathrm{Kg}$ e no $21^{\circ}$ dia na dose de $100 \mathrm{mg} / \mathrm{Kg}$ quando comparadas com o CN. O EEFHo não apresentou diferença significativa da área da lesão quando comparado com o CP no $14^{\circ}\left(50\right.$ e $75 \mathrm{mg} / \mathrm{kg}$ ) e $21^{\circ}$ dia para todas as doses analisadas, mostrando que o EEFHo apresentou o mesmo efeito cicatrizante que a pomada utilizada como CP. 
Figura 1. Média da área da lesão intergrupo da ferida após 7, 14 e 21 dias de tratamento com os controles e com o gel nas doses de 50,75 ou $100 \mathrm{mg} / \mathrm{Kg}$ do extrato etanólico das folhas de H. obovatus.

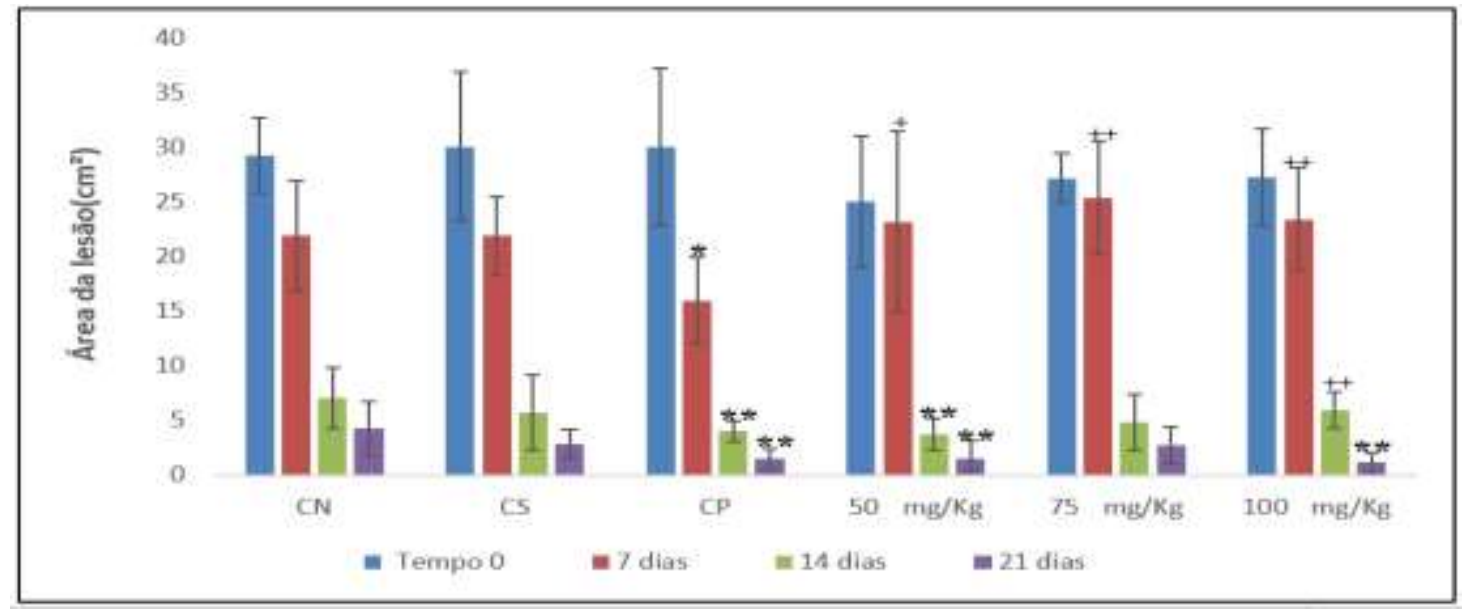

CN (controle negativo, carbapol). CS (controle do solvente, água destilada). CP (controle positivo, Nebacetin ${ }^{\circledR}$ - sulfato de neomicina $5 \mathrm{mg} / \mathrm{g}$ e bacitracina zíncica $250 \mathrm{UI} / \mathrm{g})$. ${ }^{*}$ Significativo pelo teste de Kruskal-Wallis $\left({ }^{*} \mathrm{p}<0,05 ;{ }^{* *} \mathrm{p}<0,01\right)$ quando comparado com o CN. ${ }^{+}$Significativo pelo teste não paramétrico de Kruskal-Wallis $\left({ }^{+} p<0,05 ;{ }^{++} p<0,01\right)$ quando comparado com o CP.

Fonte: Autores.

O resultado intragrupo (Figuras 2 e 3) evidenciou a redução significativa da área da ferida após 7 e 14 dias em todos os controles (negativo, solvente e positivo) quando comparados com o dia anterior. Em todas as doses do EEFHo, a redução foi significativa após 14 dias e após $21^{\circ}$ dias em $100 \mathrm{mg} / \mathrm{Kg}$.

Figura 2. Média da área da ferida intragrupo após 7, 14 e 21 dias de tratamento com os controles e com o gel nas doses de 50,75 ou $100 \mathrm{mg} / \mathrm{Kg}$ do extrato etanólico das folhas de H. obovatus.

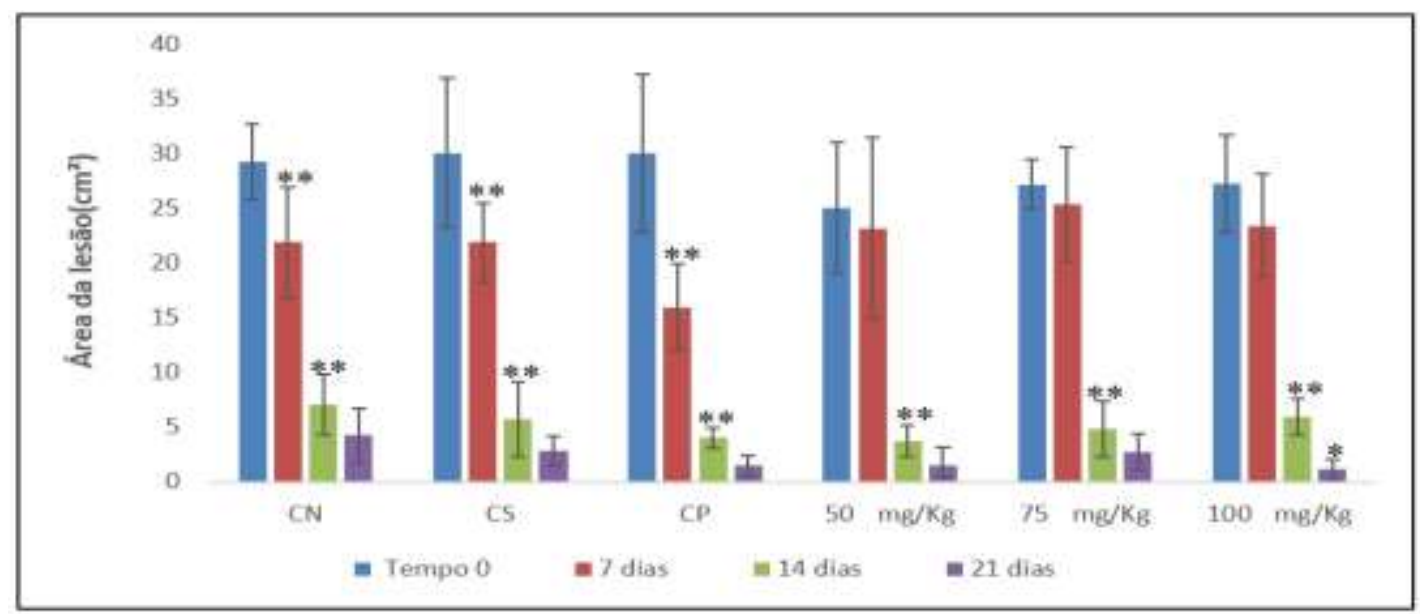

CN (controle negativo, carbapol). CS (controle do solvente, água destilada). CP (controle positivo, Nebacetin ${ }^{\circledR}$ - sulfato de neomicina $5 \mathrm{mg} / \mathrm{g}$ e bacitracina zíncica $250 \mathrm{UI} / \mathrm{g})$. ${ }^{*}$ Significativo pelo teste de Tukey $\left({ }^{*} \mathrm{p}<0,05 ;{ }^{* *} \mathrm{p}<0,01\right)$ quando comparado com o tempo anterior.

Fonte: Autores. 
Research, Society and Development, v. 10, n. 8, e29010817461, 2021

(CC BY 4.0) | ISSN 2525-3409 | DOI: http://dx.doi.org/10.33448/rsd-v10i8.17461

Figura 3. Processo de cicatrização nos períodos de 0, 7, 14 e 21 dias entre os diferentes grupos experimentais: controle negativo (G1), água destilada (G2), controle positivo (G3), $50 \mathrm{mg} / \mathrm{Kg}(\mathrm{G} 4), 75 \mathrm{mg} / \mathrm{Kg}$ (G5) e $100 \mathrm{mg} / \mathrm{Kg}$ (G6) do extrato etanólico de H. obovatus.

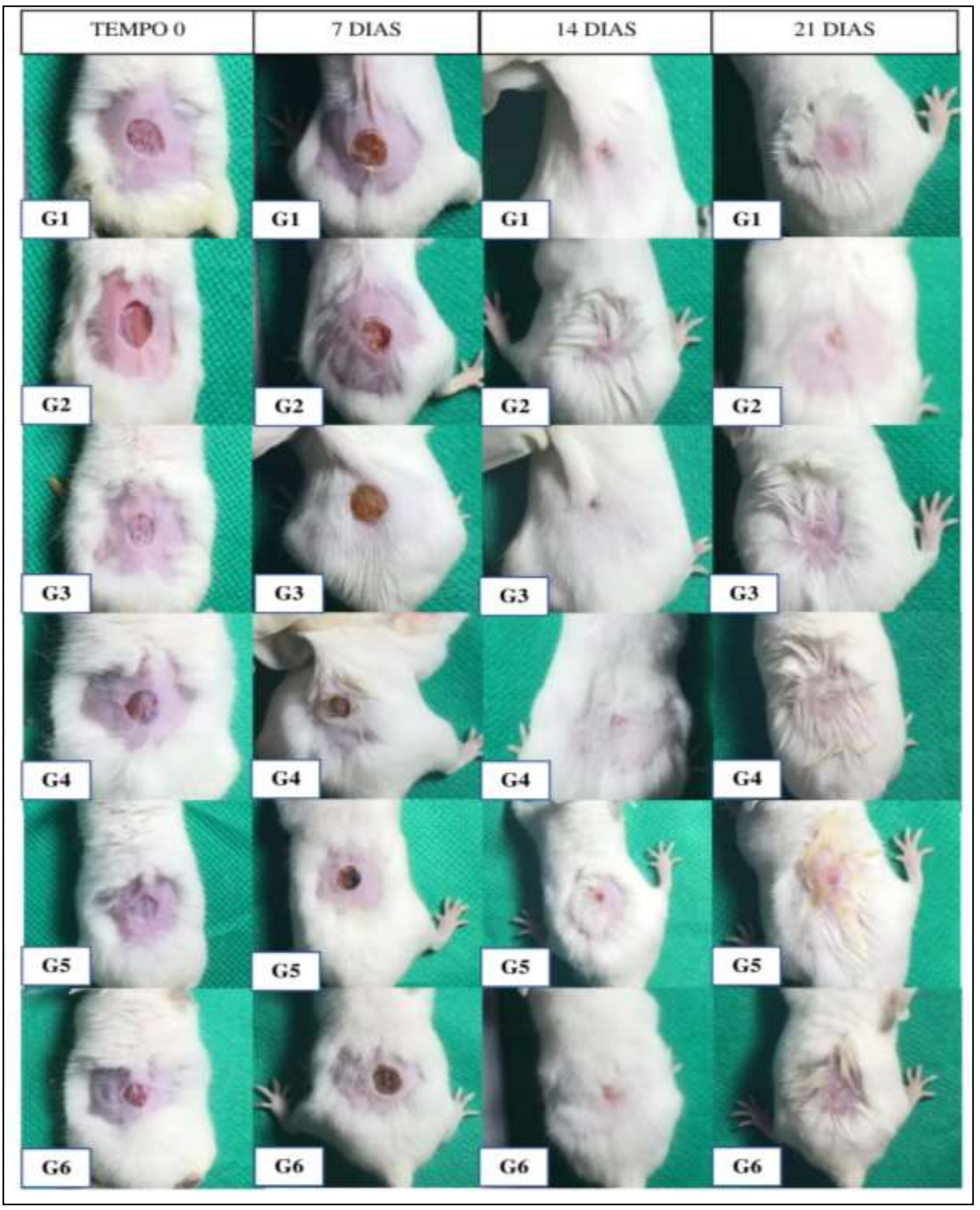

Fonte: Autores. 
Em termos histológicos, foi analisado as células polimorfonucleares (PMN) e fibroblastos após 21 dias de tratamento (Figura 4). Os resultados desta análise mostraram que não houve diferença significativa de células polimorfonucleares (PMN) (Figura 5) entre os grupos tratados com o EEFHo em comparação com os controles. O processo de cicatrização nas doses de 50 e $100 \mathrm{mg} / \mathrm{Kg}$ foi evidenciado pelo aumento significativo de fibroblastos (Figura 5) em relação ao controle negativo. Além disso, nas mesmas doses não houve diferença em relação ao CP, o que evidencia que o processo cicatrizante foi tão bom quanto a pomada utilizada. Enquanto na dose de $75 \mathrm{mg} / \mathrm{Kg}$ também não houve diferença em relação aos controles.

Figura 4. Lâminas histológicas coradas com hematoxilina-eosina (HE) (A) e Tricomio de Mansson (B) evidenciando células polimorfonucleares (PMN) (setas brancas) e fibras colágenas (seta vermelha), respectivamente.

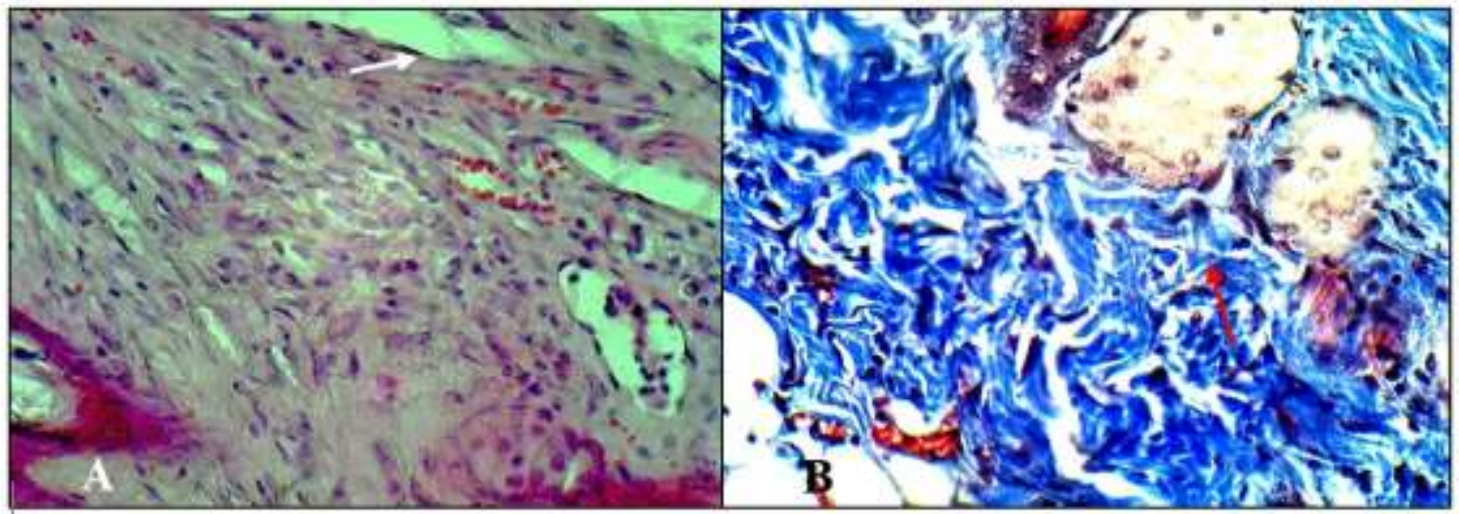

Fonte: Autores.

Figura 5. Média percentual de células polimorfonucleares coradas com Hematoxilina-Eosina e de fibroblastos corados com Tricrômico de Masson após 21 dias de tratamento com os controles e com o gel nas doses de 50, 75 ou $100 \mathrm{mg} / \mathrm{Kg}$ do extrato etanólico das folhas de H. obovatus.

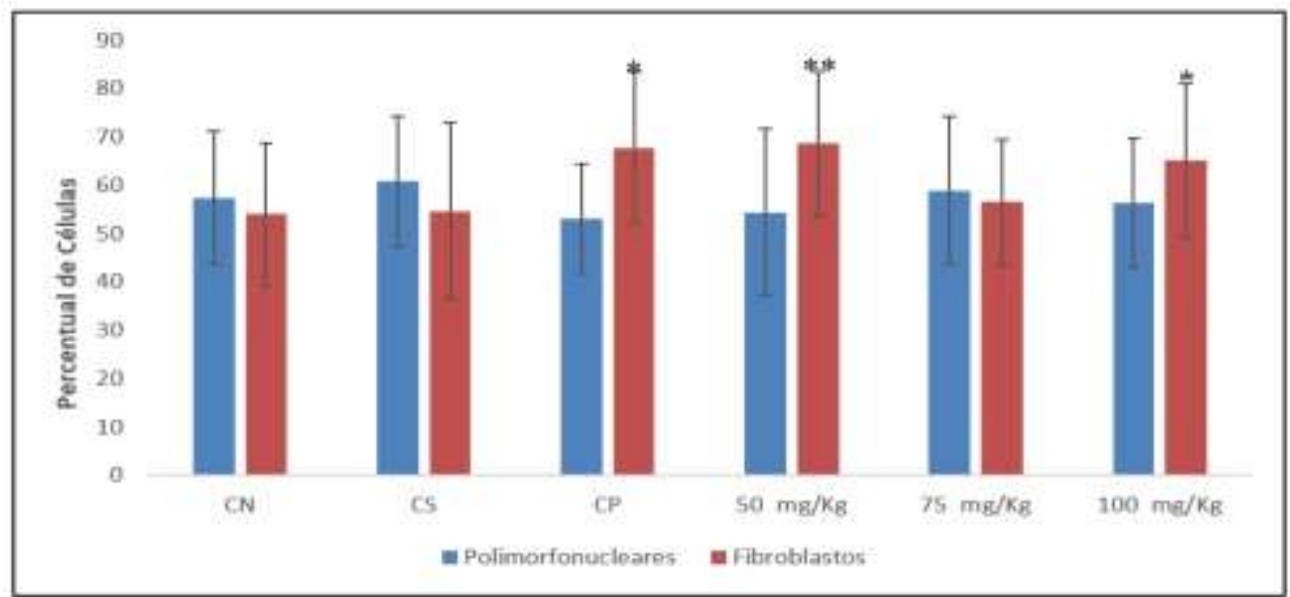

CN (controle negativo, carbapol). CS (controle do solvente, água destilada). CP (controle positivo, Nebacetin ${ }^{\circledR}$ - sulfato de neomicina $5 \mathrm{mg} / \mathrm{g}$ e bacitracina zíncica $250 \mathrm{UI} / \mathrm{g})$. ${ }^{*}$ Significativo pelo teste de Kruskal-Wallis $\left({ }^{*} \mathrm{p}<0,05 ;{ }^{* *} \mathrm{p}<0,01\right)$ quando comparado com o CN. ${ }^{+}$Significativo pelo teste de Kruskal-Wallis $\left({ }^{+} \mathrm{p}<0,05\right)$ quando comparado com o CP.

Fonte: Autores.

Em relação a área de colágeno (Figura 6), houve aumento significativo no CP e nas doses de 50 e 100 mg/Kg do EEFHo, que estão de acordo com os resultados observados na média de fibroblastos (Figura 5). Adicionalmente, não houve diferença significativa da área do colágeno em todas as doses do EEFHo quando comparado com o CP, o que reforça a produção similar de colágeno quando comparada com a pomada cicatrizante comercializada. 
Figura 6. Média da área do colágeno após 21 dias de tratamento com os controles e com o gel nas doses de 50, 75 ou $100 \mathrm{mg} / \mathrm{Kg}$ do extrato etanólico das folhas de H. obovatus.

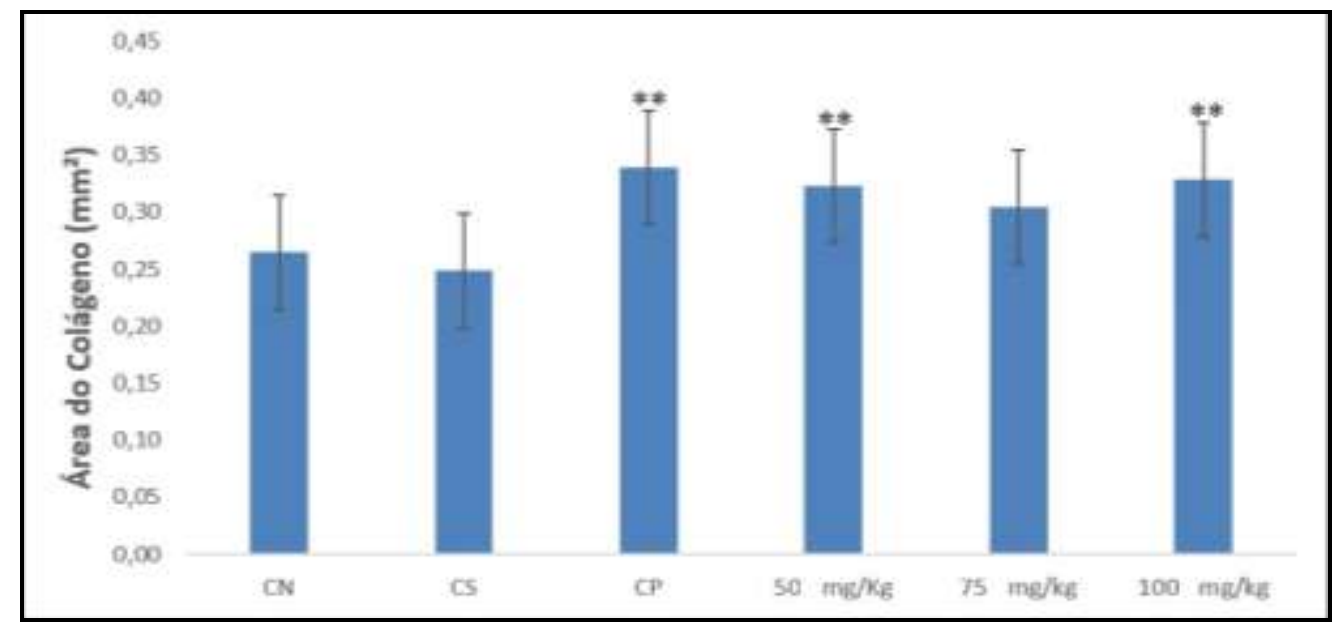

CN (controle negativo, carbapol). CS (controle do solvente, água destilada). CP (controle positivo, Nebacetin ${ }^{\circledR}$ - sulfato de neomicina $5 \mathrm{mg} / \mathrm{g}$ e bacitracina zíncica $250 \mathrm{UI} / \mathrm{g})$. ${ }^{*}$ Significativo pelo teste de Kruskal-Wallis $\left({ }^{*} \mathrm{p}<0,05 ;{ }^{* *} \mathrm{p}<0,01\right)$ quando comparado com o CN. ${ }^{+}$Significativo pelo teste de Kruskal-Wallis $\left({ }^{+} \mathrm{p}<0,05\right)$ quando comparado com o CP.

Fonte: Autores.

\section{Discussão}

As plantas medicinais são utilizadas na cicatrização de feridas (Capella et al., 2015), sendo uma prática difundida ao redor do mundo e das gerações, valorizando o uso de terapias alternativas (Faleiro et al., 2009). Além disso, cerca de $80 \%$ da população mundial dependem de plantas medicinais para os cuidados de atenção básica à saúde (Sarimahmut et al., 2016). No entanto determinadas plantas da flora nativa ainda não possuem estudos científicos comprovados ou são aplicadas de forma inadequada (Araújo et al., 2015). Em razão das diferentes finalidades terapêuticas de H. obovatus e a carência de informações científicas, o presente estudo analisou a prospecção fitoquímica e o efeito cicatrizante do extrato etanólico das folhas dessa espécie.

$\mathrm{Na}$ análise macroscópica do intergrupo, os camundongos tratados com o EEFHob mostraram regressão significativa da área da ferida (50 e $100 \mathrm{mg} / \mathrm{Kg})$, confirmando a sua eficácia no processo de cicatrização após $14^{\circ}$ e/ou $21^{\circ}$ dias quando comparadas com os grupos controles. Resultado similar foi observado por Vieira (2012) com o extrato hidroalcoolico das cascas de H. drasticus após 14 dias. Do mesmo modo, o estudo realizado por Valois (2018) demontrou que o hidrogel do latéx a $2 \%$ da H. bracteatus também foi eficaz no processo de cicatrização após 14 dias. Além disso, análise macroscópica do intragrupo no presente estudo também foi significativa, principalmente, após 14 dias para todas as doses. De forma consistente com as fases da cicatrização, os grupos controles e tratamentos apresentaram evolução com ferida de aspecto limpo e seco, sendo observado o aparecimento de crosta nas feridas em todos os animais, seguido do fechamento por completo da ferida (Vizzotto et al., 2010).

Em termos histológicos, as células PMN não mostraram diferença significativa dos tratamentos em relação aos controles após os 21 dias. Provavelmente, tal fato ocorreu, pois as células PMN no início da cicatrização são as mais abundantes na ferida pós-operatória e com o passar do processo cicatricial, as mesmas vão sendo substituídas pelos fibroblastos e fibras colágenas para a finalização da reepitelização (Giaretta et al., 2016; Kerppers et al., 2019). No estudo realizado por Souza (2015), ficou evidenciado essa substituição de células PMN por fibroblastos no processo cicatricial com o gel do látex à $2 \%$ do ápice caulinar de $H$. drasticus. As lâminas histológicas coradas com $\mathrm{HE} \mathrm{no} 2^{\circ}, 7^{\circ}$, $9^{\circ}$ e $14^{\circ}$ dias demonstraram uma diminuição significativa das células PMN com o passar do tempo e aumento significativo do número de fibroblastos e colágenos corados com tricomio de masson após $9^{\circ}$ e $14^{\circ}$ dias (Santos 2017). 
Demonstrando assim, que o resultado encontrado em nosso estudo se assemelha ao trabalho realizado por Santos (2017).

Os resultados macroscópicos quanto a cicatrização $(50$ e $100 \mathrm{mg} / \mathrm{Kg}$ ) do EEFHob, teve seus resultados corroborados pelo aumento significativo dos fibroblastos e fibras colágenas no presente estudo, uma vez que os fibroblastos são as células responsáveis pela produção de colágenos (Medeiros et al., 2016; Pereira et al., 2019). A quantidade de colágeno no final do processo de cicatrização (fase de remodelamento) foi o esperado, pois nossa análise foi realizada somente no $21^{\circ}$ dia, que ocorreu no final do processo de cicatrização (Biondo-Simões et al., 2019).

$\mathrm{O}$ efeito cicatrizante observado nos animais pode estar associado com a presença dos metabólitos secundários detectados no EEFHob, como alcaloides, taninos, fenóis e flavonoides. A presença desses metabólitos também foi relatada no látex e nas folhas de $H$. drasticus como os possíveis responsáveis pelo efeito cicatrizante e pela ação antiinflamatória, que é regulada pelo Fator de Necrose Tumoral (TNF-alfa) e pela Interleucina 2 (IL2) (Vieira, 2018). Esses metabólitos apresentam diversas atividades farmacológicas, como angiogênicas, anti-inflamatórias, antioxidantes, que aumentam a diferenciação celular e cicatrização das folhas de $H$. drasticus (Soares et al., 2016). Os metabólitos das folhas de H. obovatus provavelmente aumentaram a migração e a proliferação de células inflamatórias, pela regulação de citocinas e fatores de crescimento no processo de cicatrização, como demonstrado por Cooper (2015) em seu modelo de cicatrização de ferida.

Os metabólitos responsáveis pelo recrutamento das células inflamatórias, principalmente os taninos e alcaloides, estimulam a liberação de citocinas e fatores de crescimento que promovem a síntese de fibroblastos para a ferida (Borella et al., 2016). Os fibroblastos começam a migrar após 3 ou 4 dias, onde começam a sintetizar uma nova matriz rica em colágeno, que constitui o tecido cicatricial (Martelli et al., 2018). Assim, o objetivo deste novo tecido é, aos poucos, substituir o tecido de granulação formado durante a inflamação por um tecido conjuntivo mais forte e elástico, e posteriormente a formação da cicatriz (Islam et al., 2019; Furtado et al., 2019), assim como observado com relação aos fibroblastos e colágenos no presente estudo.

No processo cicatricial de feridas cutâneas, os taninos têm a capacidade de formar pontes de hidrogênio ou ligações hidrofóbicas duradouras com proteínas, polissacarídeos ou ambos. Com isso, ocorre a formação do complexo tanino proteína ou tanino-polissacarídeo, que por serem insolúveis em água formam uma camada protetora ou crosta sobre a lesão, permitindo que abaixo dessa camada o processo de cicatrização ocorra naturalmente. Esta capacidade de precipitação de proteínas também favorece a hemostasia após a injúria (Pristo et al., 2012). Já os flavonoides e fenóis atuam na regeneração tissular e são responsáveis pelas propriedades antioxidantes, combatendo os radicais livres, atividade antimicrobiana e moduladora do sistema imune, apresentando ação anti-inflamatória e analgésica (Barbosa et al., 2017). Os alcaloides são responsáveis por estimular a migração dos fibroblastos nas feridas (Cabral et al., 2009), além de possuir propriedades anti-inflamatórias e antioxidantes.

\section{Conclusão}

Os resultados evidenciaram que o extrato etanólico das folhas de H. obovatus foi efetivo na cicatrização em lesões cutâneas nas doses de 50 e $100 \mathrm{mg} / \mathrm{Kg}$ após 14 e/ou 21 dias com o aumento significativo de fibroblastos e fibras colágenas. Além disso, estas doses também apresentaram resultados similares a pomada que já é utilizada como cicatrizante. Provavelmente, os alcaloides, taninos, fenóis e flavonoides do extrato estão associados com o processo de cicatrização. Sendo assim, o extrato apresenta potencial para ser explorado futuramente como um fitoterápico que possa ser utilizado como gel cicatrizante. 
Ademais, estudos futuros sobre a avaliação da genotoxicidade e citotoxicidade do extrato etanólico da $H$. obovatus podem ser avaliados, o que poderá possibilitar o uso mais seguro do fitoterápico como gel cicatrizante em seres humanos.

\section{Referências}

Almeida, S. C. X., Monteiro, Á. B., Costa, G. M., \& Viana, B. G. S. (2017). Himatanthus drasticus: a chemical and pharmacological review of this medicinal species, commonly found in the Brazilian Northeastern region. Revista Brasileira de Farmacognosia, $27(6), 788-793$.

Alves, S. S. D. (2020). Humulus lupulus L.: aplicação cosmética de extratos obtidos de cones e partes vegetativas. Dissertação (Doutorado). Instituto politecnico de Bragança, Portugal.

Araújo M. A., Lemos, I. C. S., M., Menezes, I. R. A., \& Fernandes, G. P. (2015). Uso de plantas medicinais para o tratamento de feridas. Revista Interdisciplinar, 8(2), 60-67.

Ayres, M., Ayres Junior, M., Ayres, D. L., \& Santos, A. D. A. D. (2007). BioEstat: aplicações estatísticas nas áreas das ciências biomédicas. Ong Mamiraua. Belém, PA.

Barbosa, W. (2001). Manual para Análise Fitoquímica e Cromatográfica de Extratos Vegetais-Revista científica da UFPA. Belém, PA.

Barbosa, S. D. C., \& Torres, P. A. T. L. G. (2017). Metabólitos Secundários De Plantas Como Potencial Para Formulações Fotoprotetoras: Uma Revisão. Comissão Científica, 31(3), 34

Barboza, K. R. M. (2017). Avaliação do efeito do kefir sobre o dano oxidativo em camundongos submetidos à lesão gástrica. Dissertação (Doutorado). Universidade de Vila Velha, ES.

Biondo-Simões, M. D. L. P., Henning Júnior, L., Boen, B. R. D. O., Prado, J. L. D., Costa, L. R. D., Robes, R. R., \& Ioshii, S. O. (2019). Análise comparativa dos efeitos do mel, do óleo-serina de copaíba e de um produto comercial (fibrinolisina, desoxirribonuclease e cloranfenicol) na cicatrização por segunda intenção, em ratos. Revista do Colégio Brasileiro de Cirurgiões, 46(5).

Brasil. (2016). Ministério da Saúde. A Fitoterapia no SUS e o Programa de Pesquisas de Plantas Medicinais da Central de Medicamentos. Brasília, DF.

Borella, J. C., Simões, R. F., Puga, R. L. A., \& Stevanato, M. C. B. (2016). Avaliação da estabilidade e da atividade enzimática de soluções de papaína utilizadas no desbridamento e cicatrização de feridas. Infarma. Cien. Farmac, 28(3), 179-184.

Buzzi, M., Freitas, F. D., \& Winter, M. D. B. (2016). Cicatrização de úlceras por pressão com extrato Plenusdermax® de Calendula officinalis L. Revista Brasileira de Enfermagem, 69(2), 250-257.

Cabral, I. S. R., Oldoni, T. L. C., Prado, A., Bezerra, R. M. N., Alencar, S. M. D., Ikegaki, M., \& Rosalen, P. L. (2009). Composição fenólica, atividade antibacteriana e antioxidante da própolis vermelha brasileira. Química Nova, 32(6), 1523-1527.

Calero-Armijos, L. L., Herrera-Calderon, O., Arroyo-Acevedo, J. L., Rojas-Armas, J. P., Hañari-Quispe, R. D., \& Figueroa-Salvador, L. (2020). Histopathological evaluation of latex of Bellaco-Caspi, Himatanthus sucuuba (Spruce) Woodson on wound healing effect in BALB/C mice. Veterinary World, 13(6), 1045.

Capella, S. D. O. (2015). Avaliações da cicatrização de feridas abertas tratadas com Bixa orellana L. Tese (Mestrado), Universidade Federal de Pelotas, RS.

Carmo, L. D. D. (2015). Proteinas isoladas do látex de Himatanthus drasticus (Mart.) Plumel Apocynaceae reduzem a resposta inflamatória e nociceptiva na artrite induzida por zymosan em camundongos. Dissertação (Mestrado), Universidade Federal do Ceará, CE

Coelho, J. M., Antoniolli, A. B., Nunes e Silva, D., Carvalho, T. M. M. B., Pontes, E. R. J. C., \& Odashiro, A. N. (2010). O efeito da sulfadiazina de prata, extrato de ipê-roxo e extrato de barbatimão na cicatrização de feridas cutâneas em ratos. Revista do Colégio Brasileiro de Cirurgiões, 37(1), 045-051.

Cooper, R. L., Segal, R. A., Diegelmann, R. F., \& Reynolds, A. M. (2015). Modeling the effects of systemic mediators on the inflammatory phase of wound healing. Journal of theoretical biology, 367, 86-99.

Darby, I. A., Laverdet, B., Bonté, F., \& Desmoulière, A. (2014). Fibroblasts and myofibroblasts in wound healing. Clinical, cosmetic and investigational dermatology, 7, 301 .

Estrela, C. (2018). Metodologia científica: ciência, ensino, pesquisa. Artes Médicas.

Faleiro, C. C., Elias, S. T., Cavalcanti, L. C., \& Cavalcanti, Á. S. (2009). O extrato das folhas de babosa, Aloe vera na cicatrização de feridas experimentais em pele de ratos, num ensaio controlado por placebo. CEP, 29102, 770.

França, W. C. D. S. C., Souza, A. C. R. L. A. D., Cordeiro, J. A., \& Cury, P. M. (2011). Análise da ação da Himatanthus drasticus na progressão do câncer de pulmão induzido por uretana em camundongos. Einstein (São Paulo), 9(3), 350-353.

Furtado, R. A. A., Noleto, M. L. P., Pessoa, D. R., da Silva Almeida, V., Maia Filho, A. L. M., Uchôa, V. T., \& dos Santos Alves, W. (2019). Ação do gel Anacardium Occidentale L. associado ao ultrassom terapêutico no processo de cicatrização em camundongos. Saúde (Santa Maria), $45(2)$, 15. 
Gensel, J. C., \& Zhang, B. (2015). Macrophage activation and its role in repair and pathology after spinal cord injury. Brain research, 1619 , 1-11.

Giaretta, V. M. A., da Silva, A. M., Renó, A. C. M., Aguiar, D. A. F., da Silva Arantes, C. M., \& Posso, M. B. S. (2016). Proposta de uma escala para avaliar o turgor da pele de idosos. Revista Ciência e Saúde On-line, 1(1).

Griffiths, C., Barker, J., Bleiker, T. O., Chalmers, R., \& Creamer, D. (Eds.). (2016). Rook's textbook of dermatology. John Wiley \& Sons.

Islam, MS e Lucky, RA (2019). Um estudo sobre diferentes plantas da família apocynaceae e seus usos medicinais. Univers J Pharm Res , 4 (1), $42-6$.

Kerppers, I. I., Kerppers, F. K., dos Santos, K. M. M. G., Cordeiro, M. E. R., \& da Silva Pereira, M. C. (2019). Efeito do extrato aquoso de Cordyline dracaenóides Kunth na cicatrização de lesões cutâneas. Medicina (Ribeirao Preto), 52(4), 267-275.

Lima, R. A., Pinto, M. N., Mendoza, A. Y. G., da Silva, D. R., do Nascimento, F. A., Rodrigues, J. J. P., \& de Souza Assis, S. N. (2019). A Importância Das Plantas Medicinais Para A Construção Do Conhecimento Em Botânica Em Uma Escola Pública No Município De Benjamin Constant-Amazonas (Brasil). Revista Ensino de Ciências e Humanidades-Cidadania, Diversidade e Bem Estar-RECH, 3(2, Jul-Dez), 478-492.

Linhares, J. F. P., \& Pinheiro, C. U. B. (2013). Caracterização do sistema de extração de látex de janaúba (Himatanthus Willd. ex Schult.Apocynaceae), no Município de Alcântara, Estado do Maranhão, Brasil. Revista Pan-Amazônica de Saúde, 4(1), 9-9.

Lucetti, D. L., Lucetti, E. C., Bandeira, M. A. M., Veras, H. N., Silva, A. H., Leal, L. K. A., \& Viana, G. B. (2010). Anti-inflammatory effects and possible mechanism of action of lupeol acetate isolated from Himatanthus drasticus (Mart.) Plumel. Journal of Inflammation, 7(1), 1-11.

Martelli, A., Andrade, T. A. M. D., \& Santos, G. M. T. D. (2018). Perspectivas na utilização de fitoterápicos na cicatrização tecidual: revisão sistemática. Archives Of Health Investigation, 7(8), 344-350.

Medeiros, Aldo Cunha; Dantas-Filho, Antônio Medeiros. Cicatrização das feridas cirúrgicas. Journal of surgical and clinical research, 7, 87-102.

Oh, J., Byrd, A. L., Deming, C., Conlan, S., Kong, H. H., \& Segre, J. A. (2014). Biogeography and individuality shape function in the human skin metagenome. Nature, 514(7520), 59-64.

Passaretti, T., Guarnieri, A. P., Filipini, R., Alves, B. D. C. A., \& Fonseca, F. L. A. (2016). Eficácia do uso do barbatimão (Stryphnodendron barbatiman) no processo de cicatrização em lesões: uma revisão de literatura. ABCS health sci.

Pereira, A. C. A., Clemente, K. C., Silva, B. H. B. D., \& Orro, V. O. (2019). Cicatrização: uso de matriz de colágeno. Revista Brasileira de Oftalmologia, 78(4), 274-277.

Pristo, I. (2012). Cicatrização de feridas: fases e fatores de influência. Acta Veterinaria Brasilica, 6(4), $267-271$.

Ribeiro, A. P. L., \& Oliveira, B. G. R. B. de. (2019). Custo da prevenção e tratamento de feridas crônicas: um desafio para enfermagem. Revista Enfermagem Atual In Derme, 83(21).

Santos, G. J. L., Ferreira, T. C., Rodrigues, A. L. M., Freitas, J. C. C., Morais, S. M., Girão, V. C. C., \& Nunes-Pinheiro, D. C. S. (2017). Involvement of mast cells, CD68+ and VEGF+ expressions in response to Himatanthus drasticus commercial latex in mice wound healing model. Arquivo Brasileiro de Medicina Veterinária e Zootecnia, 69(3), 513-522.

Sarimahmut, M., Balikci, N., Celikler, S., Ari, F., Ulukaya, E., Guleryuz, G., \& Ozel, M. Z. (2016). Evaluation of genotoxic and apoptotic potential of Hypericum adenotrichum Spach. in vitro. Regulatory Toxicology and Pharmacology, 74, 137-146.

Silva, N. C. D., Gonçalves, S. F., Araújo, L. S. D., Kasper, A. A. M., Fonseca, A. L. D., Sartoratto, A., \& Morais, W. P. (2019). Atividade antimalárica in vitro e in vivo do óleo essencial de Cyperus articulatus (Cyperaceae). Acta Amazonica, 49(4), 334-342.

Soares, F. P., Fraga, A. F., Neves, J. P. O., Romero, N. R., \& Bandeira, M. A. M. (2015). Estudo etnofarmacológico e etnobotânico de Himatanthus drasticus (Mart.) Plumel (janaguba). Revista Brasileira de Plantas Medicinais, 17(4), 900-908.

Soares, F. P., Cavalcante, L. F., Romero, N. R., \& Bandeira, M. A. (2016). Himatanthus Willd. ex Schult.(Apocynaceae). Pharmacognosy reviews, 10(19), 6.

Sousa, E. L. D., Grangeiro, A. R. S., Bastos, I. V. G. A., Rodrigues, G. C. R., Anjos, F. B. R. D., Souza, I. A. D., \& Sousa, C. E. L. D. (2010). Antitumor activity of leaves of Himatanthus drasticus (Mart.) Plumel-Apocynaceae (Janaguba) in the treatment of Sarcoma 180 tumor. Brazilian Journal of Pharmaceutical Sciences, 46(2), 199-203.

Souza, T. D. F. G. D. (2015). Modulação da resposta inflamatória e aceleração da cicatrização de feridas cutâneas experimentais pelas proteínas isoladas do látex de Himatanthus drasticus Mart.(PLUMEL). Dissertação (Doutorado). Universidade Federal do Ceará.

Spina, A. P. (2015). Himatanthus In: Lista de Espécies da Flora do Brasil. Jardim Botânico do Rio de Janeiro.

Vale, V.V. (2014) Estudo fitoquímico e atividade antiplasmódica em Plasmodium falciparum (W2) de Himatanthus articulatus (Vahl) Woodson (Apocynaceae). Dissertação (Mestrado em Farmacologia) -Universidade Federal do Pará, Pará.

Valois, R. B. V., de Almeida, B. M., Prata, M. F., Cardoso, J. C., \& de Albuquerque-Júnior, R. L. C. (2017). Avaliação do Potencial Cicatrizante de Hidrogel Fotopolimerizável contendo extrato de Himatanthus Bracteatus (A. DC.) Woodson obtido por extração em líquidos pressurizados. Semana de Pesquisa da Universidade Tiradentes-SEMPESq, (19).

Vieira, D.A. (2012). Propriedade farmacológicas das cascas de Himatanthus drasticus (Mart.) Plumel em modelos de analgesia, inflamação e cicatrização em camundongos. Dissertação (Mestrado em Ciências da Saúde) - Universidade Federal do Maranhão, São Luís.

Vieira, P. C. (2018). Avaliação dos mecanismos associados ao efeito terapêutico de dieta rica em fibras solúveis na cicatrização de feridas cutâneas 
Research, Society and Development, v. 10, n. 8, e29010817461, 2021

(CC BY 4.0) | ISSN 2525-3409 | DOI: http://dx.doi.org/10.33448/rsd-v10i8.17461

em camundongos: papel do receptor GPR43 e da interleucina (IL)-18. Tese Doutorado em Biologia Celular da Universidade Federal de Minas.

Vizzotto, M., Krolow, A. C. R., \& Weber, G. E. B. (2010). Metabólitos secundários encontrados em plantas e sua importância. Embrapa Clima Temperado-Documentos (INFOTECA-E)

Yariswamy, M., Shivaprasad, H. V., Joshi, V., Urs, A. N., Nataraju, A., \& Vishwanath, B. S. (2013). Topical application of serine proteases from Wrightia tinctoria R. Br.(Apocyanaceae) latex augments healing of experimentally induced excision wound in mice. Journal of ethnopharmacology, 149(1), 377-383. 